\title{
Kentsel Izgara Formunun Kullanıcı Hareketlerine Etkisinin Mekân Dizim Yöntemi ile İncelenmesi Isparta Kafeler Caddesi Örneği
}

Aslihan Çetin 1

ORCID: 0000-0001-7176-6394

\author{
Eda Çelik ${ }^{2}$ \\ ORCID: 0000-0002-7121-9945
}

\author{
Şefika Gülin Beyhan ${ }^{3}$ \\ ORCID: 0000-0003-1756-1210
}

\section{Öz}

Çalışma, Isparta kent merkezinde yer alan eğlence merkezleri açısından oldukça önemli bir yere sahip olan ve kullanıcıların büyük çoğunluğunu genç kesimin oluşturduğu Kafeler Caddesi'ni kapsamaktadır. Yapısal olarak sokaklardan oluşan, ızgara formundaki alanda karşılıklı ve sıralı dükkânlar yer almaktadır. Yöntem olarak, şehirlerin algılanmasını, mekânsal oluşumu, yaya hareketlerini anlamaya, anlatmaya ve tahmin etmeye yönelik teknikler topluluğu olan Mekân Dizimi'mi (Space Syntax) kullanılmıştır. Mekân Dizimi, bulunduğu alanın ızgara yapısının, mekânları bütünleştirici etkisi üzerinde durmaktadır. Buna göre, izgara kent formlarının bütünleşme ve yaya hareketlerinde etkisinin ne olduğu önemli bir soruyu oluşturmaktadır. Yöntem kapsamında da kent ızgarasının kullanıcı hareketliliğine etkisi; alanın mekân dizim analizleri ve her bir sokak üzerinde yaya sayımları yapılarak incelenmiştir. Bu durumu değişsirecek başka bir faktör olmadığı takdirde, mekânsal oluşum, kullanıcı hareketlerinde belirleyici olmaktadır. Mekân ve kent topoğrafyası gibi olguların belirleyici olduğu bu yöntemde, çevredeki davranış biçimleri referans alınır. Bu bă̆lamda; kent ızgarasının, yaya hareketliliği üzerindeki etkisini sorgulamak, eğer varsa neler olduğunu tespit etmek çalışmanın amacını ve özgün değerini oluşturmaktadır. Çalışma sonucuna göre, sokak genişliği, mekânların fonksiyonu, yapı yüksekliği gibi kent ızgarası bağlamında değerlendirilen parametrelerin yaya hareketliliğini etkilediği görülmüştür.

Anahtar Kelimeler: Kent Izgarası, Yaya Hareketliliği, Isparta Kafeler Caddesi, Mekân Dizimi Yöntemi.

\footnotetext{
${ }^{1}$ Doktora Öğrencisi., Süleyman Demirel Üniversitesi, E-mail: mmr.aslihan.cetin@hotmail.com

2 Doktora Öğrencisi., Süleyman Demirel Üniversitesi, E-mail: edacelik1691@gmail.com

${ }^{3}$ Prof. Dr., Süleyman Demirel Üniversitesi, E-mail: gulinbeyhan@sdu.edu.tr

idealkent (c) Kent Araştırmaları Dergisi (Journal of Urban Studies)

http://idealkentdergisi.com

Geliş Tarihi Received Date: 02.04.2020 Kabul Tarihi Accepted Date: 01.12.2020
} 


\title{
Investigation of The Effect of Urban Grid Form on User Movements by Space Syntax Method Case of Isparta Kafeler Caddesi
}

\author{
Aslihan Çetin ${ }^{4}$ \\ Eda Çelik ${ }^{5}$ \\ ORCID: 0000-0001-7176-6394 \\ Şefika Gülin Beyhan ${ }^{6}$ \\ ORCID: 0000-0002-7121-9945 \\ ORCID: 0000-0003-1756-1210
}

\begin{abstract}
The study setting covers Kafeler Streets, being in a center of entertainment in Isparta. In the grid-shaped area, structurally comprised of streets, the shops are placed opposite and next to each other. Space Syntax, a collection of techniques for understanding, describing and predicting the perception of cities' spatial formation and pedestrian movements, was used. It focuses on the unifying effect of the grid structure of the area where it is located. The impact of grid city forms on integration and pedestrian movements is an important question. The effect of the urban grid on user mobility was studied by analyzing the space sequence of the area and performing pedestrian counts on each street. When other factors are homogenized, the spatial formation determines the user movements. In this method, where facts such as space and urban topography are decisive, the movement patterns in the environment are referred. Thus, questioning the impact of the urban grid on pedestrian mobility and determining what these effects are forms the purpose of the study. The study showed that urban grid parameters such as street width, functions of them and buildings' height affect pedestrian mobility.
\end{abstract}

Keywords: Urban Grid, Pedestrian Mobility, Isparta Kafeler Streets, Space Syntax Method

\footnotetext{
${ }^{4}$ PhD. Student., Süleyman Demirel University, E-mail: mmr.aslihan.cetin@hotmail.com

${ }^{5}$ PhD. Student., Süleyman Demirel University, E-mail: edacelik1691@gmail.com

${ }^{6}$ Prof. Dr., Süleyman Demirel University, E-mail: gulinbeyhan@sdu.edu.tr

idealkent (c) Kent Araştırmaları Dergisi (Journal of Urban Studies)

http://idealkentdergisi.com

Geliş Tarihi Received Date: 02.04.2020 Kabul Tarihi Accepted Date: 01.12.2020
} 


\section{Giriş}

Kentsel mekânın ilk çağlardan günümüze kadar geçen süreçteki gelişimine bakıldığında yerleşim yerlerinin dokusunu oluşturan ve iskeletini meydana getiren ulaşım sisteminin etkili olduğu görülmektedir. Var oldukları coğrafya ile bu coğrafyanın fiziksel ve topografik özellikleri kentlerin organik bir doku ile gelişmesinde etkili olmaktadır.

Organik bir şekilde gelişim gösteren kent formlarında baskın ana akslara rastlanmamaktadır (Morris, 1994). Organik kent formlarında sokakların mekânsal yapısı insanı etkilemekte, bu hareketler ise mekânın fiziksel yapısını şekillendirmektedir (Kubat, 1999). Günümüz kentleşmesinde yollar kentin dokusunu oluşturmanın yanı sıra ulaşım sistemini meydana getirme gibi işlevsel özellikleri ile tanımlanmaktadır. Kentin fiziksel yapısını meydana getiren bu sistem kullanıcıların kentsel hareketliliğini de önemli derecede etkileyen unsurlardandir.

Ticari aktiviteler ilk zamanlardan itibaren olduğu gibi günümüzde de kentin mekânsal yapısını ve dolayısıyla da kentlilerin toplumsal yapısını etkileyen unsur olmuştur. Ticaret aktiviteleri kentin, mimarisi, mekânsal, ekonomik ve toplumsal yapısıyla doğrudan alakalıdır. Bu bağlamda günümüzde yoğun ticari faaliyetlerin gerçekleştiği, sahip olduğu kentsel ızgara dokusunun, çalışmaya katkı sağlaması amacıyla Isparta kentinde yer alan ana aksın ikiye bölünerek oluştuğu Mimar Sinan Caddesi ve 6 Mart Atatürk Caddesinin çevrelediği, Kafeler Caddesi çalışma alanı olarak seçilmiştir. Kafeler Caddesi sınırları içerisinde bulunan sokaklar ise çalışmanın kapsamını oluşturmaktadır.

Kent ızgarası ve ticaret şekli yerleşim sistemi içindeki yapıların kalitesini de etkilemektedir. Arazi kullanımı, mekânsal bütünleşme ve yaya hareketliliği arasındaki ilişki yerleşmenin sosyal ve ekonomik olarak canlanmasında önemlidir. (Hillier, 1996). Bu bağlamda, çalışma alanındaki yoğun yaya hareketleri ve bu hareketleri doğuran kent ızgarası arasındaki ilişkinin çözümlenebilmesi için mekân dizimi yöntemi ile bütünleşme haritası ve yaya sayım grafikleri oluşturulmuştur.

\section{Literatür Özeti}

Mekân, insanların gereksinimleri doğrultusunda kullandıkları faaliyetlerini gerçekleştirdikleri alandır. Süregelen yaşam içerisinde de, insan ve mekân sürekli bir etkileşim içerisinde olmuştur. Bu bağlamda mekân, kullanıcı davranışlarını yönlendirmekte, insan da mekânı kendi ihtiyaçlarına göre etkilemekte ve düzenlemektedir. 
Bacon'a (1977) göre kentsel mekân zaman ve hareket olgularıyla birlikte şekillenmektedir. Mekân ile yapıların ilişkisini tarihsel veriler ile inceleyen Bacon (1967), mekânın anlam kazanması için zaman ve hareket olgularının da bir arada bulunması gerektiğini ifade etmektedir. Hareket olgusu insanın bir parçası olduğu evrende meydana gelen değişimlerin mekân üzerine yansımasıyla oluşmaktadır. Kentsel mekânda yerleşimin dokusunu oluşturan temel unsurlardan biri hareketin meydana geldiği ve kurgulandığı dolaşım sistemidir. $\mathrm{Bu}$ bağlamda kentsel mekân oluşum sürecinde kent kullanıcılarının hareket ilişkileri dâhilinde bağlantılar oluşturulmaktadır (Roberts ve Greed, 2001).

Ulaşım ve dolaşım sistemlerinde yaya hareketlerini de şekillendiren bağlantılar kentin imgesel açıdan okunabilir olmasında doğrudan etkilidir. Okunabilirlik insanların mekânı ne derece kolaylıkla anlayabildiğini ölçen ve ifade eden bir kavramdır (Lynch, 1960). Kentsel mekânda okunabilirlik insanların mekânı algılayış biçimlerinde belirleyici olmaktadır. Meydanlar, yüksek katlı ya da geniş yapılar, kamu binaları, kent mobilyaları, özgün peyzaj unsurları ve tüm bu unsurların etrafında yerleştiği ulaşım sistemi ile yollar mekânın okunabilir olmasında etkili olmaktadır (Moughtin ve diğerleri, 1999). Bu noktada mekân dizim yöntemine değinmek yerinde olacaktır.

1970 yllinda Bartlett School of Architecure and Planning ve University College London'da, Bill Hillier ve Julienne Hanson liderliğinde bir ekip tarafından ortaya atılan 'Mekân Dizimi' kent ve yapı ölçeğinde inşa edilmiş mekânların matematiksel hesaplamasını yaparak mekânı anlama, algılama, anlatma ve kullanıcı hareketlerini tahmin etmeye yönelik geliştirilen bir kuramdır. 1984'te Hillier ve Hanson tarafından yazılan 'The Social Logic Of Space' (Mekânın Sosyal Mantığı) kitapta bahsedildiği gibi mekân dizimi; sosyal yapı ve mekân arasındaki ilişkiyi anlamaya yönelik bir yöntemdir (Hillier ve Hanson, 1984).

1970'li yıllara kadar, morfolojik çalışmalarda kurulan ilişkiler sadece kentin fiziki bileşenleri ile olmuştur. Bu konuda: İtalya'da Muratori (1959), Aymonino ve Rossi (1966); İngiltere'de MP Conzen (1969) gibi mimar ve coğrafyacıların çalışmaları katkı sağlamış, Fransa'da Versailles okulunun çalışmaları ile daha da hızlanmıştır. Kent planlama, mimarlık, coğrafya, felsefe, sosyoloji gibi birçok alanda çalışmalar bulunmaktadır. Mekân dizim metodu, mekân analizlerinde sadece fiziksel verilerin değil sosyal verilerinde önemli olduğunu göstermektedir (Özbek, 2007). Geliştirilen bu yöntem diğerlerinden farklı olarak hem tasarım öncesine hem de kullanım sürecine dair veriler sunmaktadır.

Mekân dizimi; sosyal yapıyı ve mekânı sayısal olarak açıklamak ve karşılaştırmak olarak tanımlanabilir. Günümüzde sadece fiziksel verilerin mekânı tanımlayabileceği kabul edilse de, insan hareketlerinin yönü ve şekillenmesinin 
mekân tasarımında oldukça önemli olduğu bilinmektedir. Tüm kapalı ve açık mekânların kullanıcıları insanlardır ve onların sosyal mantı̆ı mekânın oluşumunda belirleyici olmaktadır (Özbek, 2007).

Atak (2009), mekân dizim analizini, yapılı çevrenin, mekânsal düzeni analiz edilerek, mekânsal biçimlenme özelliklerini ve altta yatan sosyal yapının tanımlanması olarak açıklarken; Gündoğdu (2014), mekânsal konfigürasyonun, kullanıı hareketleri ve görüş alanı ile ilişkisini fiziksel olarak ele alınmasıyla, insanları yönlendirme ve bir araya getirme potansiyelini ortaya koyma şeklinde tanımlamaktadır. Çil (2006) ise, özellikle kentsel açık alanlarda, görüş alanı ve insan hareketlerini çakıştırarak bir arada toplanma durumunu açıklama olarak görmektedir.

Analiz yöntemi, geometrik olandan ziyade, topolojik düzlemde mekânsal konfigürasyonu anlamamızı sağlar. Öncelikli hedef, mekân içindeki harekete bağlı olarak, insanları bir araya getirebilme potansiyelini açıklamaktır (Şıkoğlu ve Arslan, 2015).

Mekân dizimi analiz yöntemi günümüze kadar, nesneler ve nesnelerin birbirleri ile ilişkilerini ya da bireyler ve mekânsal deneyimlerini ele alarak, konut yapılarında ve çeşitli yapılarda pek çok ölçeklerde uygulanmıştır. Yöntemin konut yapıları dışında uygulamaları şu şekildedir;

- Kentlerin, kompleks fiziksel yapılarını tanımlama,

- Yaya hareketleri ve kentsel yapı arasındaki ilişkiyi anlama, bu doğrultuda yeni tasarmm fikirleri ortaya koyma,

- Yaya hareketlerine bağlı olarak yol bulma (way-finding) ve mekân okunabilirliği (intelligibility),

- Karmaşık fonksiyonlu kültür yapılarında hareketin çözümlenmesi ve planlama,

- Bir yapı veya aktivite alanı için yer seçimi ve bu alanın harekete etkisi bağlamında kente etkisine çıarım,

- Suç-mekân ilişkisi,

- Ortak alanların kullanımı ve ulaşılabilirlik,

- Mekâna ilişkin mahremiyeti kavrama,

- Mekâna ilişkin içe kapalılık/ dışa açıklık kavramlarının irdelenmesi (Çil, 2006).

Hillier ve Hanson (1998) mekân dizimi yöntemini, tek yapıdan kentsel ölçeğe kadar, yapıların ve kentlerin mekânsal dokularını anlamak için kullanılan ve mekân ile sosyal yapıyı birleştiren önemli bir bilimsel yaklaşım olarak tanımlar (Hillier ve Hanson, 1998). David Seomon'a göre mekân dizim yönteminin aynı zamanlarda ortaya çıkarılan farklı yaklaşımlardan ayıran en önemli 
özelliği, mekânı anlatırken kullanılan tekniklerin aslında 'kullanıcı deneyimlerine' dayanması şeklinde açıklamıştır (Şıkoğlu ve Arslan, 2015).

Mekân dizim yöntemi, kent gramerini ve tasarımını farklı matematiksel değerlerle analiz ve tarif eder. Kentsel bir mekânda, insan hareketlerinin yönleri, toplanma alanları ve doğrultuları mekânın geometrisinin meydana getirdiği sisteme göre belirlenir (Özbek, 2007; Pafka ve diğerleri, 2018; Netto, 2016). Bu bağlamda, kentsel biçimlenmenin bir başka deyişle kent ızgarasının, kullanıcı hareketlerine etkilerinin var olduğu bilinmekte ancak neler olduğu ve nasıl etkilediği açık değildir. Bu nedenle, kent ızgarasını tanımlamak, insan ve mekânlar arasındaki ilişkiyi açıklamak bir araya gelişlerini anlamamıza yardımcı olacaktır. Bu ilişkiyi ortaya koyma adına son yıllarda mekân dizim yöntemine dayalı çeşitli araştırmalar yapılmıştır. Kim (2002), cadde konfigürasyonu ile ofis binalarının arazi kullanım yoğunluğu arasındaki ilişkiyi ele almış ve konfigürasyonun şehirlerin oluşumunu etkilediğini göstermiştir. Baran (2008), modern ve geleneksel mahaller ve yayaların hareket ilişkisini inceleyerek, sokak tasarımının yaya davranışlarını açıklamada önemli bir rolü olduğunu; Xia (2013) de, mekansal konfigürasyonun yaya davranışlarına etkisi üzerinde durarak, doğal sokak tabanlı topolojik analizin, insan hareketlerinin anlamada iyi bir yöntem olduğunu söylemiştir. Koohsari (2014), parklar ve kamusal açık alanlar üzerinden, yapılı çevre ve aktivite arasındaki bağlantıya bakarak arazi kullanım ve ticari destinasyonların varlığının kullanıcıların fiziksel aktivitesiyle ilgili olduğunu; Can (2015), binalar ve caddeler arasındaki ara mekanların farklı kentsel biçimlerde sosyal etkileşimim nasıl etkilediği araştırmış ve bu ara mekanların özellikle daha entegre alanlarda sosyal etkileşimi ve insanları bir arada bulundurma sıklığını arttırdığı sonucuna ulaşmıştır. Choi ve Koch (2015) de kentsel form ve kullanıı davranışının ilişkisini anlamaya çalışmış, konfigürasyon ve çekiciler gibi hareket davranışını etkileyen kentsel biçimin ana faktörlerinin, hareket davranışını karakterine (hareket amacı) göre etkileme derecesinde farklılıklar gözlemlemiştir. Koohsari (2016) çalışmasında iki sokak ağı üzerinden yaptığı analizde cadde entegrasyonu ve yürüyüş ilişkisini analiz ederek, analiz sonucunun yürüme sıklı̆̆ ile pozitif ilişkili olduğunu bulmuştur. Ratti (2004) ise, birçok çalışmada kullanılan mekân dizim yönteminin tutarsız olduğu durumları ortaya koymuştur. Örneğin, çeşitli analizlerin yapıldığı yöntem ile bina yükseklikleri ve arazi kullanımı gibi bileşenleri hesaplamanın zor olduğunu bildirmektedir. Ancak günümüzde hesaplamanın kolaylaşması ile kentsel dokunun daha derinden anlaşlabileceğini de vurgulamaktadır. 
Yöntemin en belirleyici özelliği, elde edilen analiz değeri (bütünleşme) yardımıyla, kent motfolojisi ve yaya hareketliliği arasındaki ilişkiyi ortaya koymasıdır (Teklenburg ve diğerleri, 1993). Analizlerin yapılması, tasarıma işlevsellik kazandırılması, hareketliliğe göre yeniden şekillendirilmesi, yeni tasarımların neler getirebileceğinin öngörülmesi, ara alanların değerlendirilmesine yardımcı olur (Güler, 2007). Bu nedenle kentsel mekânların değerlendirilmesinde önemli yer tutmaktadır.

Kentsel bir yerleşmede, yayalar görülen en uzun görüş aksı üzerinde hareket ederler. Sistemde en uzun ve en kısa doğruların meydana getirdiği haritalar oluşturulur. Böylece sistemin uzunluğu metre cinsinden değil, doğruların sayıları ile ifade edilir (Hillier, 1999; Rotti, 2003). Yerleşime giren yayalar açıların en az olduğu doğrusal akslar üzerinde yürürler, dolayısıyla görüş mesafelerine göre hareket ederler. Aksiyel haritalar, esas olarak görüş haritalarıdır ve kesişen aks sayıları bütünleşme ile doğru orantılı olarak artar. Bütünleşme ise, sistemdeki her doğrusal aksın diğer akslara olan ortalama derinliğini ifade eder (Çetin, 2019). Bir başka deyişle kök derinliğinin, diğer düğüm noktaları ile olan matematiksel ortalamasıdır. Bütünleşme değeri yüksek mekânların ulaşılabilirliği fazla, derinliği azdır. (Hillier, 1983) Bütünleşme haritalarında kırmızı renkten mora doğru azalan bütünleşme değeri söz konusudur. Yani kırmızı renk en fazla bütünleşme değerine sahipken, mor renk en düşük bütünleşme değerine sahiptir (Menderes, 2014). Bu noktadan hareketle, Kafeler Caddesi bütünleşme haritaları oluşturulmuştur. Hareketi yönlendiren mekân oluşumu ve kullanımı gibi morfolojik özellikler, yaya hareket dokusuna ve sokak kalitesine etkileri açısından önemli veriler sunmaktadır.

\section{Metot}

Analiz çalışmalarında, seçilen sokaklar üzerinde, hafta içi ve hafta sonu günün en yoğun olduğu belirlenen öğle saatinde, her sokakta yarım saat süreyle yaya sayımları yapılmıştır. Doğal yaya hareketliliğini anlamak için yapılan sayımda yayaların; yaş, cinsiyet gibi demografik bilgileri ve yerleşimi kullanım amacı dikkate alınmamıştır. Buna göre çalışma kapsamında ele alınan 1001, 1002, 1003, 1004, 1005 ve 1006 no'lu sokakların yaya yoğunlukları şekil 1'de verilmiştir. 


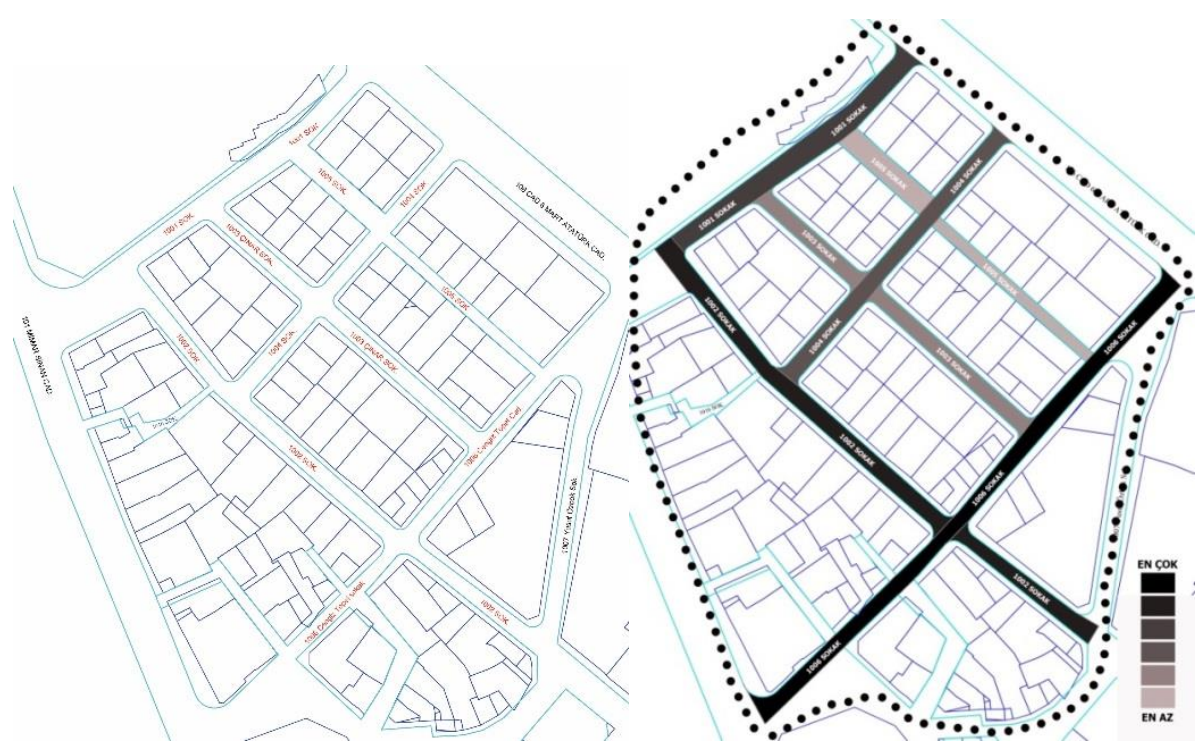

Şekil 1. Analizlerin yapıldığı sokaklar ve yaya yoğunlukları haritası

Alan içerisinde bulunan her bir sokağın sistem içindeki ve birbirleri ile olan ilişkisini anlamak için aksiyel bütünleşme haritaları çıkarılmıştır. Yerleşim alanının plan şeması doğal yaya hareketliliğinde etkili olmaktadır. Yapılan sayım ve analizlere göre, 1001 sokağın, sistem içerisinde az bütünleştiği görülmektedir. Yaya sayıları da bu durumu destekler niteliktedir ve toplam yaya sayısının \%16'lık kısmını oluşturmaktadır.

Tablo 1. Kafeler Caddesi Yaya Sayımları (Yazarlar tarafından oluşturulmuştur)

\begin{tabular}{llll}
\hline $\begin{array}{l}\text { Sayım yapılan } \\
\text { sokak adı }\end{array}$ & $\begin{array}{l}\text { Hafta içi toplam } \\
\text { yaya sayısı }\end{array}$ & $\begin{array}{l}\text { Hafta sonu toplam } \\
\text { yaya sayısı }\end{array}$ & $\begin{array}{l}\text { Yaya sayım değişimi } \\
\mathbf{( \% )}\end{array}$ \\
\hline 1001 sokak & 454 & 755 & $\% 66$ \\
\hline 1002 sokak & 752 & 1102 & $\% 46$ \\
\hline 1003 sokak & 380 & 539 & $\% 41$ \\
\hline 1004 sokak & 328 & 766 & $\% 133$ \\
\hline 1005 sokak & 143 & 201 & $\% 40$ \\
\hline 1006 sokak & 757 & 1300 & $\% 72$ \\
\hline & Ortalama=469 & $\begin{array}{l}\text { Ortalama= 777 } \\
\text { Standart sapma= 391.96 }\end{array}$ & Ortalama=\%66 \\
\hline
\end{tabular}

Kafeler Caddesini öğrenci ve asker nüfusun genelde eğlence amaçlı kullandığı bilinmektedir. Buna göre, tablo-1 ve şekil 2'de görüldüğü gibi, 1001 sokak üzerinde bütünleşme değerinin düşük ve yaya sayımını az olması bu durumla bağlantılıdır. Ayrıca çalışma dahilindeki diğer sokaklar araç trafiğine kapalı iken, 1001 sokağın araçlar için bir geçiş noktası oluşturması sonuçları mümkün kılmaktadır. 
Genişliğin fazla olduğu sokaklardaki yüksek bütünleşme değeri, mekânların kolay ulaşılabilir, derinliğin az, bağlantllllı̆ın yüksek olduğunu gösterir. Buna göre, 1002 sokağın diğer sokaklara kıyasla fazla olan sokak genişliği, sokak üzerinde farklı işlevlere sahip mekânların bulunması ve alanın bir girişinin bu sokak üzerinden sağlanması sebebiyle, \%25'lik yüksek bir oranda yaya sayımı gerçekleşmiştir. Ayrıca, 1002 sokağın orta kısmında ne fazla yaya sayımı yapılmıştır. Çünkü, burada yoğun hareketliliğe fazla mekan sayısı sebep olmuştur.

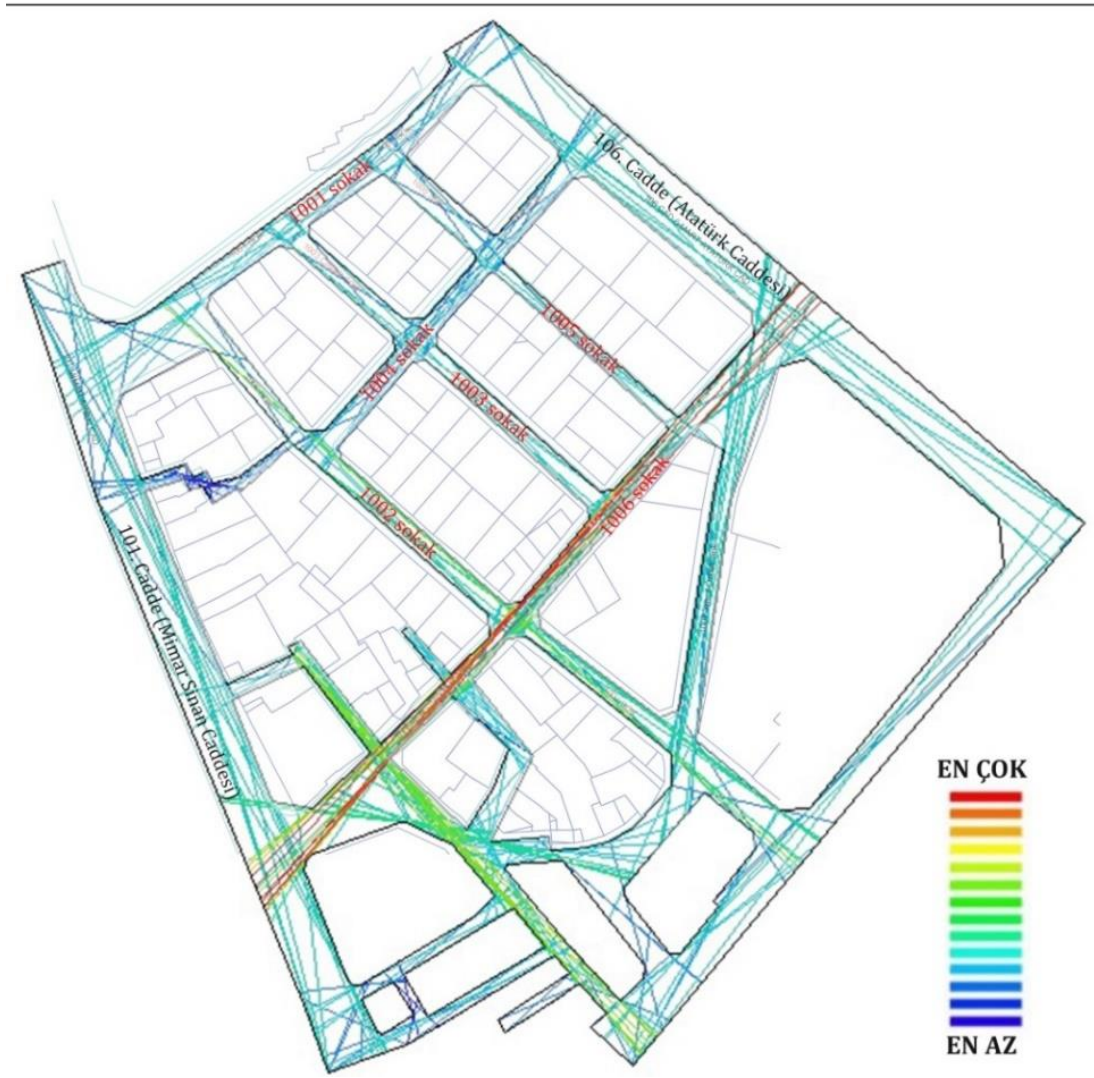

Şekil 2. Kafeler Caddesi R3 Bütünleşme Haritasi

Yerleşimde amacına göre daha alt işlevlere sahip mekânların bulunduğu sokaklarda yaya sayımları az, bütünleşme değeri düşük olarak karşımıza çıkmaktadır. 1003 sokak da daha çok eğlence amaçlı tercih edilen yerleşim içerisinde, kırtasiye ve kitapevlerinin yoğun bulunduğu sokak olmaktadır. Bu sebeple, sokakta \%12 oranında yaya sayımı yapılmıştır. Diğer sokakların kesişi- 
min de bulunan bu sokağın, işlevi dışında sadece geçiş amaçlı olarak kullanıldığı da bilinmektedir. Ayrıca 1003 sokağın genişliğinin 1002 sokakla benzer olmasına rağmen daha dar algılanma sebebi, sokak üzerinde yer alan mekânların yaya yoluna taşması olduğu düşünülmektedir. Dolayısıyla bu durum, hareketliliği etkilemektedir (Bk. Şekil 3). Farklı işlevli mekânların bulunmadığı yemeiçme-eğlence (kafe-bar) mekânlarının yer aldığı 1004 sokakta \%15’lik bir oranda yaya sayımı yapılmıştır. Sokağın en yoğun sayım yapılan noktası, yerleşime girişin sağlandığı 1002 sokak ile kesişim noktasıdır. Yaya sayım oranının çok yüksek olmaması, sokak üzerinde işlev açısından çeşitliliğin az olduğu mekânların yer almasından kaynaklanmaktadır.

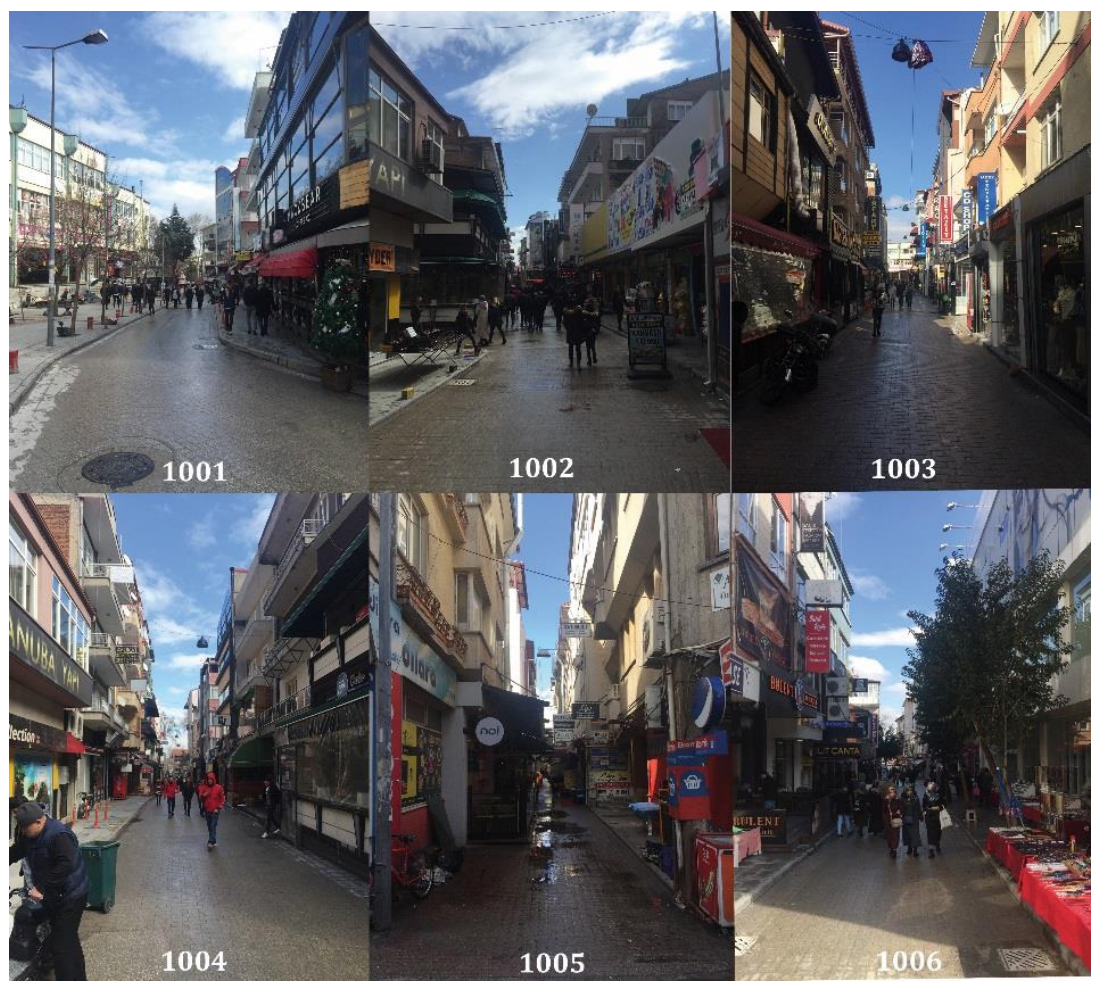

Şekil 3. Sayım yapılan sokak yoğunlukları (Kaynak: Yazarlar).

Yapıların oldukça yoğun ve yüksek katlı olduğu sokaklarda sokak genişliğinin de dar olması karanlık ve güvensizlik hissi yaratmaktadır. Bu durumun gözlemlendiği 1005 sokakta da sistem içerisinde \%5'lik oranla en az yaya sayımı yapılmıştır. Ayrıca bu sokakta görüş mesafesinin kısa olması, minimum düzeyde tercih edilebilir kılmaktadır. Sokak genişliğinin az olmasından dolayı birbirine çok yakın yüksek katlı yapılar, sokağa güneş ışığının girmesine engel 
olmakta, böylece yaratth̆ lanmasina sebep olmaktadır.

Çıkarılan bütünleşme haritasında, 1006 sokağın en yüksek değere sahip olduğu görülmektedir. Yayalar hareketleri boyunca bilinçli bir şekilde azalan eğim yönünü tercih ederler. Bu bağlamda, 1006 sokağın en uzun görüş mesafesine sahip olmasi, yüksek kotta yer alan kamusal bir toplanma alanına bağlanması ve bu kamusal alanda ibadet yapısının yer alması ve daha düşük kottaki bir kesişim noktasına ulaşması en yüksek bütünleşme değerine sahip olma nedenidir. Yapılan yaya sayımlarında da hem hafta içi hem de hafta sonu hareketliliğin en fazla olduğu sokak olmuştur. Ayrıca 1006 sokağın Mimar Sinan Caddesine yakın noktasında yapılan sayımlarda hareketliliğin en fazla olması, bu noktada yer alan asker nüfusuna hitap eden seyyar satıcıların bulunması ve farklı bir girişinde buradan sağlanmasıdır. Dolayısıyla 1006 sokağın axial line bilişsel mekân etkileri en yüksek yaya yoğunluğunun burada olmasını açıklamaktadır.

Grafik 1'de, birim zamanda hafta içi ve hafta sonu sayılan yaya nüfusunun göstermektedir.

Grafik 1. Hafta içi ve hafta sonu toplam yaya sayımları grafiği

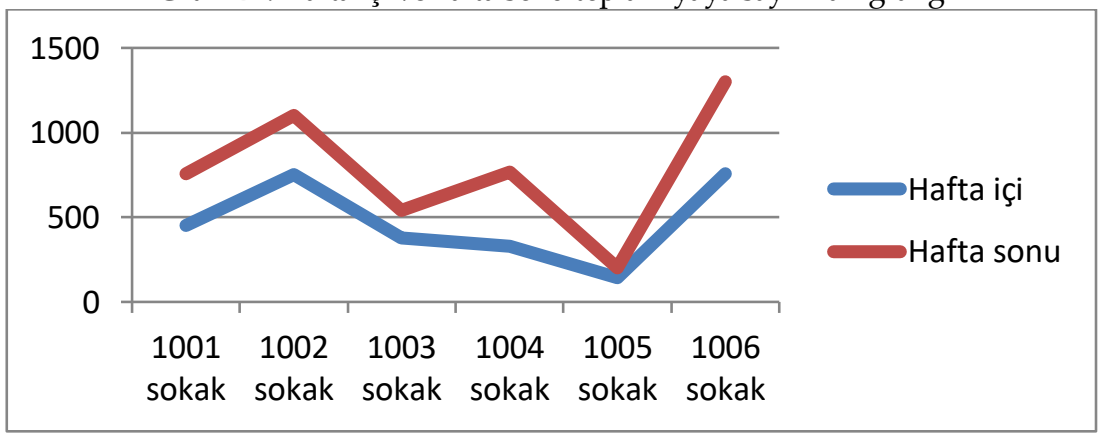

Hafta içi ve hafta sonu yapılan yaya sayımlarda hareketliliğin birbirinden farklı olduğu görülmektedir. Kullanıcıların çoğunluğunu öğrencilerin oluşturduğu varsayımını, hafta içi ders saatlerinde yapılan yaya sayımları doğrulamaktadır. Hafta sonu yapılan sayımda ise, hareketliliğin her bir sokakta farklı olmakla birlikte ortalama \%66 oranında arttğı görülmüştür. (Bk. Tablo 1)

\section{Tartışma ve Sonuçlar}

Çalışma' da, Isparta kent merkezinde yer alan, hareketli yerleşim dokusu ile farklı işlevleri barındıran 'Kafeler Caddesi' ele alınmıştır. Değişen mekânsal fonksiyonlara rağmen, aynı yerleşim düzeni ve kimliği korunmaktadır. Yerleşim alanlarının strüktürel yapılarının ve sokak dokularının, sosyal ilişkileri 
oluşturmasındaki etkisi çalışmanın amacını oluşturmaktadır. Bir başka deyişle kentsel ızgara formunun kullanıcı hareketlerine ve mekân fonksiyonlarına etkisini araştırmaktır. Kentsel form ve hareket arasındaki karmaşık ilişkinin sorgulanması çalışmanın hipotezini ortaya koymaktadır.

Kentsel yerleşmelerde mekânsal oluşumun mantığını, kullanıcılarının kültürel değer ve sosyal yaşantısında bulmak mümkündür (Aydınlı, 2004). Buna göre, Özbek (2007)'in çalışmasında olduğu gibi; ticaret fonksiyonları açısından, arazi kullanımı ve mekân kalitesinin topoğrafyadan etkilenmediği görülmüştür. Kafeler Caddesi hali hazır haritaları üzerinden yapılan bütünleşme haritalarında, en bütünleşmiş aksın eğim yönünde uzanan sokak olduğu sonucuna ulaşılmıştır.

Yayaların, çevrelerine baktıklarında en uzun görüş mesafesine sahip oldukları aks üzerinde yürümeyi tercih ettikleri görülmüştür. Bütünleşme haritalarından hareketle, en bütünleşmiş aksın aynı zamanda kırılma olmadan devam eden en uzun görüş mesafesini oluşturduğu bilgisine ulaşılmıştır.

Yapılan bütünleşme analizi ve yaya sayımlarına göre; bütünleşme, yaya hareketleri ve ortaya koydukları davranış şekilleri ile ilgilidir. Dolayısıyla yerleşme formunun oluşumunda bu davranış şekilleri etkili olmaktadır. Bu durum 1002 ve 1006 sokakta, hem bütünleşme değerinin hem de yaya sayımlarının yüksek olması sonucuyla desteklenmektedir. Ayrıca doğal yaya hareketleri ticareti yönlendirerek, farklı çekim noktalarının oluşmasını sağlamakta ve mekân kalitesini etkilemektedir. Bu sonuç, Choi ve Koch' un (2015) ve Hillier ve Lida'nın (2005) da bahsettiği gibi kentin strüktürel yapısının gözlemlenen hareketlilik ile bağlantılı olduğu bulgusuna paralellik göstermektedir. Başka bir ifadeyle 1006 sokağın yapısı ve alandaki dizilimde yer aldığı eksenel hatt, bilişsel mekân etkileri en yüksek yaya yoğunluğunun burada olmasını açıklamaktadır.

Aksiyel analiz haritalarında bütünleşmesi yüksek olan sokakların, erişilebilirliğin ve okunabilirliğin en fazla olduğu alanlar olduğu varsayımına göre, hareketliliğin de daha çok olması mümkündür. Buna göre, 1006 sokağın en bütünleşik ve en yoğun hareket dokusuna sahip aks olduğu analiz sonuçlarında görülmüştür. Ayrıca 1006 sokak en uzun görüş mesafesine sahip aks üzerinde yer almaktadır.

Kafeler Caddesi'nde, hafta içi ve hafta sonu yapılan yaya sayımlarında, yüksek farklılık dikkat çekmektedir. Bu farklılık, \%133'lük en fazla artış ile 1004 sokakta ve \%40'lık en az artış ile 1005 sokakta ortaya çıkmıştır. 1004 sokakta hafta sonu sayımlarında yaşanan bu önemli değişime, kullanıcılarının öğrenciler olduğu düşüncesine göre sokak üzerinde bulunan yeme-içme-eğlence 
mekânlarının sebep olduğu açıktır. Baran (2008)'ın olası bir açıklaması da, kullanıcıların araç trafiğinin daha az, bütünleşmenin ve erişilebilirliğin düşük olduğu cadde ve sokaklarda daha fazla eğlence amaçlı bulunduğudur. Buna göre, hafta sonu özellikle 1004 sokakta daha yüksek yaya sayısına ulaşılması, öğrencilerin yoğunluklu olarak eğlence amaçlı kullandığı sonucuna ulaştırmıştır. Ayrıca, yapılan sayımlarda her sokakta farklı sayılara ulaşılması kent ızgara formunun yaya hareketliliğinde etkili olduğunu göstermiştir.

Ticaret faaliyetlerinin yoğun olduğu alanlar, aynı zamanda yoğun hareket dokusunu içermektedir. Yol seçeneği az olan yayalar, belirgin bazı sokaklar üzerinde yoğunlaşır ve diğer sokaklarda bulunan işletmeler bu durumdan olumsuz olarak etkilenir (Kepenek, 2011). Ancak Xiana (2017) çalışmasında, ticari fonksiyonların homojenize edilerek insan akışı dağlımının dengelenebileceği sonucuna ulaşmıştır. Ratti (2004) ise, bazı alanların çok düşük bütünleşme ve bağlantıllı̆̆ğa sahip olmasına rağmen, buralarda oluşturulan çekim noktalarının hareketi etkilediğini göstermiştir. Buna göre, yaya hareketlerinde yerleşimin fiziksel bileşenleri (sokak genişliği, yapı yüksekliği, sokaklar arasında oluşan kısa yollar, aydınlatma, sokak doğrusallığı) kadar mekânların ticari fonksiyonları ve konumları da önemli olmuştur. Ratti (2004)'de olduğu gibi 1004 sokakta bütünleşme değerinin düşük olmasına rağmen eğlence mekânlarının yoğun olarak yer almasıyla çekim noktası haline gelerek, özellikle hafta sonu yaya sayımlarının fazla olduğunu göstermiştir. Şekil 4'te de bu duruma ilişkin mekânsal işlev analiz haritası verişmiştir. 


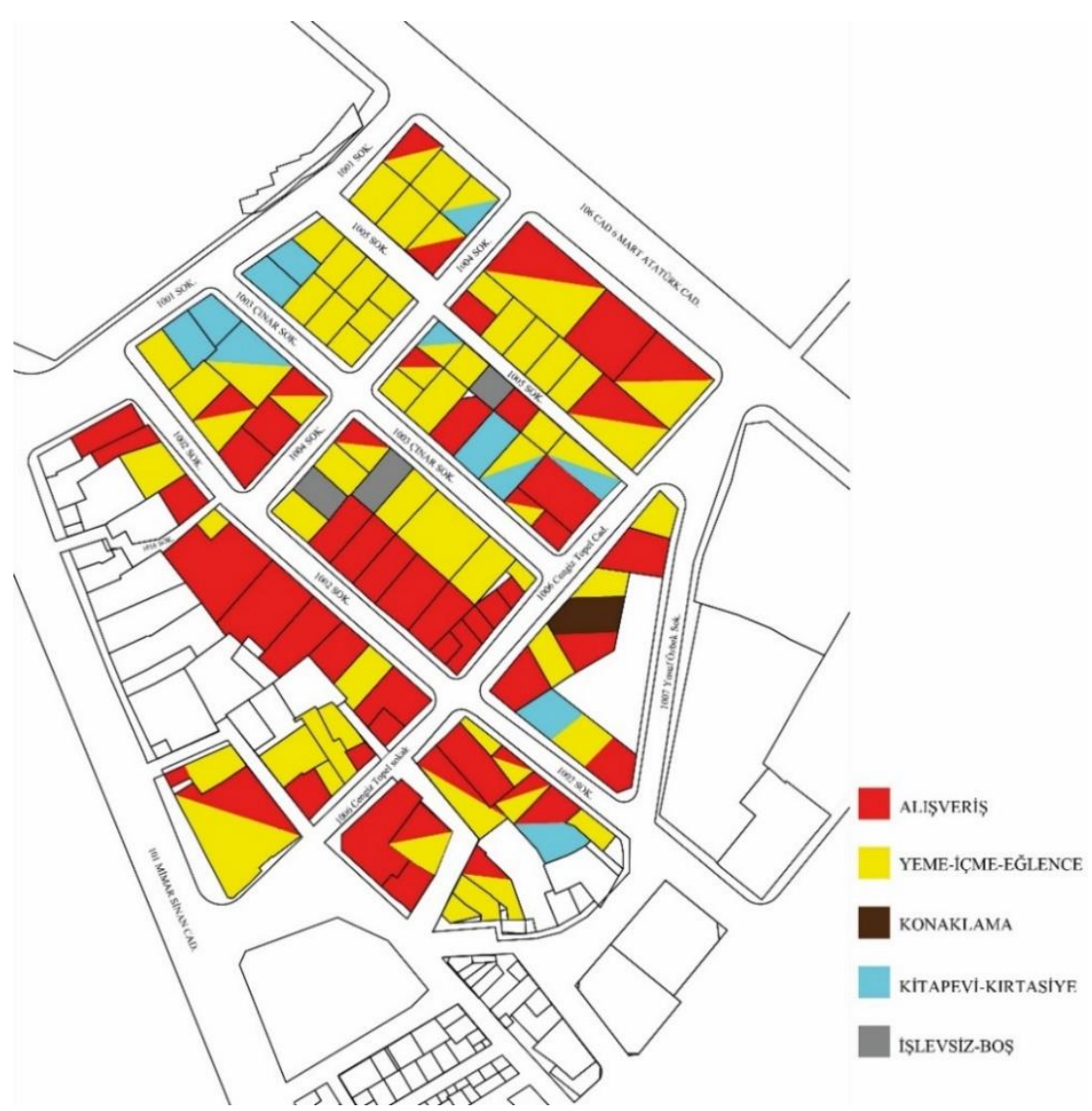

Şekil 4. Kafeler Caddesi mekânsal işlev analiz haritası

Mekânsal işlev haritasından hareketle en yoğun yaya sayımlarının yapıldığı 1002 ve 1006 sokakta alışveriş (Giyim, kozmetik, bijuteri, parfümeri mekânları v.s) mekânlarının öne çıktı̆ı̆ görülmektedir. Buna göre, kullanıcıların bu sokakları daha çok alışverişe-ğlence-geçiş amaçlı kullandığı sonucuna varılmaktadır. Ayrıca bu sokakların genişliğinin ve doğrusallı̆̆ın en fazla olması, giriş noktalarına ve kamusal toplanma alanlarına bağlanması en yoğun olmalarının bir başka sebebidir.

Yaklaşık olarak aynı oranda sayım yapılan 1001 ve 1004 sokak mekânsal işlev açısından farklılıklar göstermektedir. 1001 sokak üzerinde kitapevi ve kırtasiyeler yer alırken, 1004 sokakta yoğun olarak yeme-içme-eğlence mekânları yer almaktadır. İşlev açısından 1004 sokağın daha yoğun olması öngörülmesine rağmen 1001 sokağın daha yoğun olması şaşırtıcı bir sonuca ulaştırmıştır. Bu durumun nedeninin, 1001 sokağın Mimar Sinan Caddesi ve 6 Mart Atatürk 
Caddesi arasında doğrudan yaya ve araç bağlantısının olması olduğu düşünülmektedir.

Çalışmada da yaya hareketlerinin, bulunulan sokaktaki genişlik, mekânsal işlev, yapı yüksekliği, güvenlik duygusu, aydınlatma gibi olgulardan etkilenebildiği 1003 ve 1005 sokak analiz ve yaya sayım sonuçlarında görülmüştür. Bu nedenle yayaların, çevresine baktığında ulaşabildiği en uzun görüş mesafesi boyunca hareket ettiği düşünülmektedir. Bu durum yayalar tarafından oluşturulan güvenli bir hareket dizisini vermektedir. Karanlık ve kapalı vistaya sahip olan sokakların, yarattı̆̆ belirsizlik hissinden dolayı tercih edilebilirliği düşüktür. Bu bağlamda, 1003 ve 1005 sokak yaya sayımlarına göre hareketliliğin en az olduğu sokaklardır. 1003 sokağın genişliği daha fazla olmasına rağmen yaya yoluna taşmış mekânların olması ve 1005 sokağın dar, birbirine yakın yüksek katlı yapıları barındırması güvensizliğin artmasına sebep olduğu düşünülmektedir.

Lynch'in (1988) öngördügü gibi, yerleşimin formu, kullanıcı hareketlerini yönlendirerek, ticareti dolayısıyla mekânların çekiciliğini etkilemektedir. Bu çekici noktalar, özellikle karışık mekânlarda yayaların yürürken algılayabildikleri ve kendi belirledikleri yönlendirici referanslardır. Bu durum Ratti'nin (2004); 'bina yükseklikleri hareketi değiştirir' sonucuna vardığı çalışmasını destekler niteliktedir. O halde, bütünleşme kavramı topografik olarak olduğu kadar görsel olarak da önemlidir. Sonu görülebilen en uzun mesafe, güven hissinin en yüksek, kaybolma hissinin en düşük olduğu aksları işaret eder. Dolayısıyla, bu çalışma da; Baran (2008)'e benzer şekilde kent ızgarasının, kullanıcı hareketleri üzerinde etkisinin var olduğu sonucunu ortaya çıkarmaktadır. Ancak bu çalışmanın kapsamı veri ve analizler açısından oldukça sınırlı tutulması sebebiyle, konu hakkında daha kesin sonuçlar elde edebilmek için daha fazla araştırma yapılması gerekmektedir. 


\title{
Extended Abstract
}

\section{Investigation of The Effect of Urban Grid Form on User Movements by Space Syntax Method Case of Isparta Kafeler Caddesi}

\author{
Aslihan Çetin \\ Eda Çelik \\ Şefika Gülin Beyhan \\ ORCID: 0000-0001-7176-6394 \\ ORCID: 0000-0002-7121-9945 \\ ORCID: 0000-0003-1756-1210
}

When looking at the development of urban spaces in the period from the early ages to the present day, it is seen that the transportation system that forms the texture of the settlements and creates the skeleton is effective. With the geography in which they are located, the physical and topographic characteristics of this geography are influential in the development of cities with an organic texture. In organic urban forms, the spatial structure of the streets has an impact on people, their movements shape and the physical structure of the space (Kubat, 1999). Furthermore, commercial activities have an influence on the spatial structure of the city, and thus the social structure of the city people, as it has been since the early days. The urban grid and trade style also affect the quality of the structures in the settlement systems. The relationship between land use, spatial integration and pedestrian mobility is important in the social and economic revival of settlement (Hillier, 1996). In this context, to analyze the relationship between the intense pedestrian movements in the study area and the urban grid that caused these movements, the integration map and pedestrian count charts were created with the spatial arrangement method.

The Space Syntax is a theory which was developed in 1970 at the Bartlett School of Architecture and Planning and University College London, led by Bill Hillier and Julienne Hanson, to understand, perceive, explain and predict user movements via mathematical calculations of urban and building-scale spaces. 'The Social Logic Of Space', written by Hillier and Hanson, a series of 
spaces as mentioned in the book, is a method for understanding the relationship between social structure and space (Hillier and Hanson, 1984).

Space Syntax can be defined as explaining and comparing the social structure and space numerically. The users of all indoor and outdoor spaces are people, and their social logic is a determining factor in the formation of the spaces (Özbek, 2007). Hillier and Hanson (1998) describe the space syntax method as an important scientific approach combining space and social structure, which are used to understand the spatial textures of structures and cities, from single structure to urban scale (Hillier and Hanson, 1998).

The space syntax method analyzes and describes urban grammar and design with different mathematical values. In an urban space, the directions, gathering areas and the patterns of human movements are determined according to the geometrical system of the space (Özbek, 2007; Pafka et al., 2018; Netto, 2016). Therefore, identifying the urban grid and explaining the relationship between people and places help us understand their coming together. The most distinctive feature of the method is that it reveals the relationship between urban morphology and pedestrian mobility with the help of the resulting analysis value (integration) (Teklenburg et al., 1993).

In this context, Mimar Sinan Street and 6 Mart Atatürk Street, where intensive commercial activities take place and where the urban grid texture is formed by splitting the main axis in Isparta city to contribute to the work, have been selected as the working area of Kafeler Streets. In the analysis conducted within the scope of the study, pedestrian count was carried out on the selected streets for half an hour at noon, which was determined to be the busiest of the day on weekdays and at the weekends. To understand the relationship of each street in the area within the system and with each other, an axial integration map has been drawn.

According to integration analysis and pedestrian count, integration is related to pedestrian movements and the patterns of their movement. Thus, these behaviors are influential in the formation of the settlement form. Furthermore, natural pedestrian movements shape the trade, ensure the formation of different attraction points and affect the quality of space. This result is in parallel with the finding that the structural construction of the city is related to the observed mobility as stated by Choi and Koch (2015) and Hillier and Lida (2005).

According to the results of the pedestrian count on Kafeler Streets, a high difference has been noticed between weekdays and weekends. It is clear that 
this significant difference is caused by the food and drink-entertainment venues located on the street since their consumers are students. A possible explanation is from Baran (2008) stating that pedestrians go to places, where the traffic and integration level is low and so is the accessibility, more for entertainment. Moreover, the fact that different numbers were reached on each street showed that the city grid form was influential in pedestrian mobility.

The areas where trade activities are intense also include intensive movement texture. The most intensive pedestrian count was made in the streets where the users were present mostly for shopping-entertainment-transit purposes and where stores (clothing, cosmetics, bijouterie, perfumery places, etc.) stand out. In addition, the width and linearity of these streets are the other reasons which make them the busiest places since they are connected to entry points and public gathering areas. In the study, it was seen in the analysis and the pedestrian count results that pedestrian movements can be affected by factors such as the width of the street, functional purposes of spaces, building height, sense of security and lighting.

As Lynch (1988) predicted, the form of the settlement affects the attraction level of the spaces by forming the user movements. This is because Rati (2004) claims that "building height changes the movement". Hence, the concept of integration is both visually and topographically important. If the furthest point/end point of a street is visible, it marks the axles with the highest sense of confidence and the lowest sense of feeling lost. Therefore, this study is also similar to Baran (2008) who puts forward that the city grid has an impact on user movement. However, since the scope of this study is very limited in terms of data and analysis, more research is required to obtain more accurate results on the concerned subject.

\section{Kaynakça/References}

Atak, O. (2009). Mekân dizim ve görünür alan bağlaminda geleneksel kayserievleri. Yüksek lisans tezi. YÖK ulusal tez merkezi. (251907)

Aydınl, S.(2004). Epistemolojik açıdan mekan yorumu. A. Şentürer, Ş. Ural, A. Atasoy (ed). Mimarlkk ve Felsefe içinde. (s.40-51). Yapı Yayınları, İstanbul.

Bacon, E. N. , (1967). Design of cities. Thames and Hudson LTD, Londra.

Baran, P.K.., Rodriguez, D. A., ve Khattak, A. J. (2008). Space syntax and walking in a new urbanist and suburban neighbourhoods, Journal of Urban Design, 13(1), 5-28.

Can, I., ve Heath, T. (2015). In-between spaces and social interaction: a morphological analysis of Izmir using space syntax. Journal of Housing and the Built Environment, 31(1), 31-49.

Çetin, A. (2019). Antalya bölgesinde yer alan beş yıldızh otellerin mekân dizim (space syntax) yöntemi ile incelenmesi. (Yüksek lisans tezi). YÖK ulusal tez merkezi. (557405). 
Choi, E., ve Koch, D. (2015). Movement and the connectivity of streets: A closer look at route distribution and pedestrian density. In 10th International Space Syntax Symposium, SSS 2015; University College London(UCL) London; United Kingdom. The Bartlett School of Architecture, University College London.

Çil, E. (2006). Bir kent okuma aracı olarak mekân dizim analizinin kuramsal ve yöntemsel tartışması. MEGARON. YTÜ Mim. Fak. E-Dergisi, 1(4), 218-233, İzmir.

Güler, G., (2007). Boğaz Köprülerinin İstanbul Açı Alan Sistemi Üzerine Yaptı̆̆ı Etkilerin Space Syntax Yöntemi ile Irdelenmesi. Yüksek Lisans Tezi, İ.T.Ü. Fen Bilimleri Enstitüsü, İstanbul.

Gündoğdu, M. (2014). Mekân dizimi analiz yöntemi ve araştırma konuları. Art-Sanat 2, 251275, İstanbul.

Hillier, B. (1983). Space syntax: a different urban perspective. Architects Journal, 138(48) 4763.

Hillier, B. (1996). Cities as movement economies. Urban Design International, 1 (1), 41-60.

Hillier, B., Hanson, J., (1998). A note on the intuiting of form: three ussues in the theory of design. Environment and Planning B, 25th Anniversary Issue, 3, London.

Hillier, B., (1999). The hidden geometry deformed grids: or why the space syntax works, when it looks like it should not. Environment and Planning: Planning and Design, 26(169), London.

Hillier, B., ve Iida, S. (2005, September). Network and psychological effects in urban movement. International Conference on Spatial Information Theory içinde (s. 475-490). Springer, Berlin, Heidelberg.

Kepenek, E., (2011). Antalya tarihi kent merkezi ve yakın çeoresinin mekân dizim metodu ile incelenmesi. (Yüksek lisans tezi). YÖK ulusal tez merkezi. (339146).

Kim, H. K., veSohn, D. W. (2002). An analysis of the relationship between land use density of office buildings and urban street configuration: Case studies of two areas in Seoul by space syntax analysis. Cities, 19(6), 409-418.

Koohsari, M. J., Kaczynski, A. T., Mcormack, G. R., ve Sugiyama, T. (2014). Using space syntax to assess the built environment for physical activity: Applications to research on parks and public open spaces. Leisure Sciences, 36(2), 206-216

Koohsari, M. J., Sugiyama, T., Mavoa, S., Villanueva, K., Badland, H., Giles-Corti, B., ve Owen, N. (2016). Street network measures and adults' walking for transport: Application of space syntax. Health $\mathcal{E}$ place, 38, 89-95.

Kubat, A. S. , (1999). Morphological History of Istanbul, Urban Morphology. Journal of the International Seminar on Urban Form, 4, pages 27-40.

Lynch, K. , (1960). The rmage of the city. The MIT Press, Cambridge.

Lynch, K. (1988). Image of the city. Cambridge Massachusetts: MIT Press.

Menderes, F., (2014). Cumhuriyet döneminde yerel yönetim binalarının kamusal erişilebilirlik açısindan mekân dizimi (space syntax) yöntemiyle irdelenmesi. Yüksek lisans tezi. YÖK ulusal tez merkezi. (389429)

Morris, A.E.J. (1994), History of Urban Form before Industrial Revolutions, Longman Scientific and Technical, John Wiley\&Sons Inc., New York, ABD. 
Netto, V. M. (2016). 'What is space syntax not?'Reflections on space syntax as sociospatial theory. Urban Design International, 21(1), 25-40.

Moughtin, C., Cuesta, R., Sarris, C., Signoretta, P. (1999), Urban Design: Method and Techniques, Butterworth and Heinemann Ltd., Oxford.

Özbek, Ö.Ö., (2007). Fiziksel mekân kurgularmın sosyal ilişkiler üzerinden arnavutköy yerleşimi bütününde mekân dizimi (space syntax) yöntemi ile incelenmesi. Yüksek lisans tezi. YÖK ulusal tez merkezi. (213920)

Pafka, E., Dovey, K. ve Aschwanden, GD (2020). Kentsel tasarım için mekân söz diziminin sınırları: Eksenellik, ölçek ve sinuosite. Çevre ve Planlama B: Kentsel Analiz ve Şehir Bilimi , 47 (3), 508-522.

Ratti C. (2003). Urban texture and space syntax: some inconsistencies. Environment and Planning B: Planning and Design, 31(4), 2

Ratti C. (2004). Space syntax: some inconsistencies. Environment and Planning B: Planning and Design, 31(4) 487-499.

Roberts, M, Greed, C. (2001). Approaching Urban Design: The Design Process.Longman Press, Londra.

Şıkoğlu, E., ve Arslan, H., (2015). Mekân dizim (space syntax) analizi yöntemiyle ilgili teorik bilgiler ve mekân dizim analizi yönteminin coğrafyada kullanılabilirliği. Türk Coğrafya Dergisi, 65, 11-21.

Teklenburg, J., A., F, Timmermans, H., J., P., ve Wagenberg, A., F., (1993). Space Syntax: Standardised Integration Measures and Some Simulations, Environment and Planning B: Planning and Design, 20, 347-357.

Xia, X. (2013). A Comparison Study on a Set of Space Syntax based Methods: Applying metric, topological and angular analysis to natural streets, axial lines and axial segments. Degree project thesis, Master.

Xiana, H. (2017). Simulation of Pedestrian Flow in Traditional Commercial Streets Based on Space Syntax. Procedia Engineering, 205, 1344-1349 